\title{
Relation between Trust Level and Success of Electronic Commerce and Role of Accounting in this Relation- Perception of Albanian Virtual Buyers
}

\author{
$\mathrm{PhD}$ candidate: Shqiponjë Açka \\ Lecturer of accounting in University "A. Xhuvani", Elbasan, Albania \\ ackashqiponja@yahoo.com
}

\section{Doi:10.5901/mjss.2014.v5n10p686}

\section{Abstract}

\begin{abstract}
Foreign studies show that the increases of the confidence level of virtual buyers tend to raise their purchases, and for this reason electronic commerce represent success. According to these studies the factors that may bring positive impact by increasing the level of trust are numerous and complex. The purpose of this study is to determine what perceptions have Albanian virtual buyers for the linkage between the level of trust and success of virtual model of trade and what role can play accounting in this linkage. The study will assess the perception of virtual buyers in Albania, perception that will be tested through questionnaires addressed to this target group. The questionnaire's data will be analyzed through statistical methods in order to derive conclusions of this paper. Among the statistical methods uses of parametric and non-parametric methods are depending on the degree in which are the data of this study.
\end{abstract}

Keywords: E-commerce, accounting, trust, Albanian virtual buyer's perception

\section{Introduction}

Previous studies that have examined trust in business relationships have identified the important role that faith the success in a long-term commercial relationships. For example, note that trust increases cooperation, affecting in more open communications and wider dissemination of information between the parties (Cummings and Bromiley 1996; Doney and Cannon 1997; Morgan and Hunt, 1994; Ring and Van de Ven 1994, Smith and Barclay 1997).

Furthermore, Granovetter (1985), states that the density and cohesion of social networks influence the evolution of trust in trade relations. Faith based on competencies is related to building confidence on skills of trading partners, technical knowledge and the ability to realize the commercial relationship using the internet correctly. Trading partners who demonstrate skills in producing products and services of high quality and timely delivery of information to other trading partners, helping them to have a good cooperation with distribution networks and make decisions strategic, are more likely to be reliable.

McAllister (1995), states that we are who we choose to believe it and in what circumstances. This choice is based on the recognition (interpersonal trust), through investigation of security level of indicators such as trust and seriousness. When are accessed expectations regarding reliability and security, confidence begins to shift to emotional base such as care and concern. Thus, in terms of economic indicators trust is related to the benefits that can be obtained by trading partners such as lowering costs and reducing time of trading transactions conducted through virtual networks. On the other hand, lack of confidence can lead to increased costs because trading partners need more time to be trained to implement correctly virtual transactions.

Provided trust expresses the confidence that create trading partners who having enough knowledge to other trading partners can make predictions and judgments based on past experience. Benefits that receive trading partners such as the general satisfaction and information distribution affect the increased level of confidence. Thus, continuous positive behaviors create familiarity with trading partners by increasing the perceived trust of them.

Faith based on goodwill expressed faith-based on care, interest, honesty and goodwill of trading partners. To increase the level of trust trading partners should invest in the sensitivity of trade relations created. Faith based on goodwill is characterized by an increase in levels of collaboration, open communications growth, wider distribution of information; these are the factors that lead to higher levels of participation in virtual model of trade. Long-term investments and investment in building the reputation create for trading partners the opportunity to provide trust based on goodwill. In contrast, lack of trust in goodwill leads to the destruction of trade agreements and creating a bad reputation for trading partners. 
In a study performed by Kim and Tadisina (2007) sampled by 21 studies conducted from 1999 to 2006, is noted that the existing literature has examined the support of third parties, company reputation, quality of service, quality of websites, and familiarity tend to believe, as the main factors that influence consumer trust in the virtual model of trade. However, customer perceptions influence their trust (Jarvenpaa and others, 2000; Lee and Turban 2001).

Based on the literature we can say that there is a mutual positive relation between trust and success of electronic commerce. On the one hand, increasing the level of trust leads to increased sales bringing the success of virtual model of trade and in turn the success that can be accomplished a website where is done electronic commerce increases the confidence level of virtual consumers. Expressed in graphical connection the relation is as follows:

Figure 1.1: The mutual relation between level of trust and success of electronic commerce

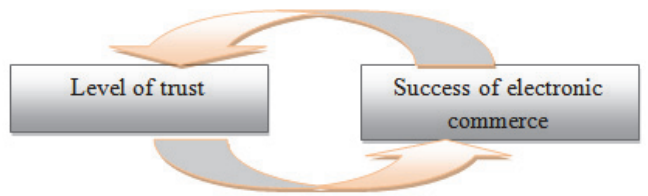

However the link that exists between the level of trust and success of electronic commerce remains not only at the theoretical perception and observation. Various researchers have built statistical models to express the relationship that exists between the level of consumer confidence and the success of electronic commerce. Given that the main factors influencing the level of trust are many, researchers have preferred to study the link trust - electronic commerce through implementation of various statistical and econometric analyses.

Thus, researchers Gao and Wu (2010), Joubert and Van Belle (2013), Egger (2003), Halaweh (2012), Brown and Jayakody (2008), Palvia (2009), Hsu and Wang (2008), Yoon (2009 ), Coles (2010), McKnight, Choudhury and Kacmar (2002), etc. have preferred to express numerically the connection trust level - success of electronic commerce using factorial analysis and structural analyses. These models are among the most favorite models by researchers for expressing relationships between factors and confirmation of hypotheses raised in their studies.

Other researchers such as Ho (2007), Corbitt, Thanasankit and Yi (2003), Metzger (2004), Eid (2011), etc. have used the correlation coefficients to study the relationship trust - success of electronic commerce. ANOVA analysis model was also a favorite of researchers to verify the connection that exists between the level of consumer confidence and the successful application of electronic commerce. Researchers Wan, Alagar and Ibrahim (2013) have used CS algorithm authentication mathematical model of connectivity, while Shi, Bochmann and Adams, have preferred stochastic models since according to their faith and behavior resembles a stochastic process.

\section{Analiza e rangjeve për studimin e lidhjes nivel besimi - sukses i tregtisë elektronike sipas perceptimeve të blerësve virtualë në Shqipëri}

Despite many studies that are conducted by foreign authors to express whether there and how strong is the link between the level of trust consumers to make purchases and success of virtual model of trade, we think to study this relation taking as data perceptions of Albanian virtual customer. To study the relationship that exists between the level of trust and success of virtual commerce by buyers in Albania we have used non-parametric methods of ranking. The main reason why we use non-parametric methods for controlling hypothesis is: The data used in the study will belong to the nominal level and can not be used to implement control hypothesis with parametric methods.

Customer responses to the questionnaires addressed to Albanian virtual buyers have served like data for the study that we have conducted. We have conducted 211 surveys in total but only $203^{1}$ responses of which are available for study.

The hypothesis that we rose in the study based on data from the literature review is:

\footnotetext{
Ha: Albanian virtual shoppers perceive that there is a strong correlation between the level of consumer confidence to participate in purchases effected through virtual networks and the success of trade that has carried through these networks
}

\footnotetext{
1 In eight other questionnaires or is not selected no answer or is selected more than one. For this reason these are considered invalid questionnaires for the study.
} 
To determine whether or not this hypothesis stands, signs criterion is non-parametric methods used in the case when the number of units included in the study is greater than 20 .

The main assumptions of the study:

- Distribution of data would be considered having normal distribution (Z) since are satisfies two conditions that are relevant in this method

1. $x=0.5^{*} n=0.5^{*} 203=101.5>5$

2. $\sigma^{\prime}=\sqrt{0.25} n=\sqrt{(0.25)} * 203=7.124>5$

Where respectively:

$\mathrm{n}$ - Number of units included in the study $=203$ units

$\mathrm{x}$ - Average of data

o - Standard deviation

- The second assumption concerns to the permissible level of error $a$.

In the case of our study allowed level of error of assuming equal by $0.05(a=5 \%)$. This error level allowed, expresses his influence in determining the value of theoretical ${ }^{2}$ statistics. To check the hypothesis according to the criterion method of sign must be found two statistics, factual and theoretical, comparison between them will tells us if the alternative hypothesis raised in the study is confirmed or not. The formulas used for finding and Ztheoretical and Zfactual according to this method are:

$$
\begin{gathered}
\mathrm{Zf}=\frac{\mathrm{x}-\mu}{\sigma} \\
\mathrm{Z}_{\mathrm{t}}=\mathrm{Z}_{0.5-50.05}=\mathrm{Z}_{0.45}=1.65 \text { s.d }
\end{gathered}
$$

Results of the study after replacing indicators in the formula are:

$$
\begin{aligned}
& Z_{f}=14.25 \mathrm{~s} . d \\
& Z_{t}=1.65 \mathrm{~s} . d,
\end{aligned}
$$

Were $\mu=0$ because before the results the $H_{0}$ is accepted like real

Based on the survey results, as Zfactual> Ztheoretical, is accepted that the alternative hypothesis, Ha, is affirmed. So, according to this study, for Albanian individuals ${ }^{3}$ who currently use the virtual model of trade ${ }^{4}$ the success of electronic commerce is positively affected by the level of trust that buyers create in virtual pages.

Since individuals haven't the same level of education, we continued studying further. The hypothesis that we set up is:

\section{HA1: The perceived level of trust in the virtual pages where trade is realized depends from the level of education}

Based on the same limitation that the data are largely nominal, also for studying the veracity of this hypothesis we will use non-parametric methods, namely Criterion Cruscal-Wallis ${ }^{5}$. Assumptions made above are valid also for this study,

\footnotetext{
2 The value of theoretical statistics is found in statistical tables.

${ }^{3}$ In the study that we conducted through questionnaires, the category which is selected as the target group are individuals who currently make purchases via the Internet. No businesses were selected because we think that individuals like virtual trade buyers have high impact on the success of electronic commerce in the Albanian site and the perception of this group can positively influence the involvement of businesses like buyers in virtual model of trade. However, this selection we have done by limiting the study population can be considered as a limitation of this study.

${ }^{4}$ According to questionnaire all asked buyers realize purchase in foreign site and none of them attempted to carry purchases in Albanian site.

${ }^{5}$ This criterion is used to control when hypotheses have more than two populations. In our case, we the asked group is divided into three categories by level of education: higher education, secondary education and others (includes those who have less education than secondary education). Table with details of questionnaires and corresponding ranks for the three study populations is reflected in the annex of the paper. For setting rank are implemented the rule: the smaller value have the first rank and for the same values are summed the ranks and the sum is divided with their number, it serves as the average value of the same range of values. For example, lowest value is 3 and there are six 3 , to determine rank alongside of 3 we collected $1+2+3+4+5+6$ and their sum is divided by 6 .
} 
So:

- Distribution of data is assumed to be normally distributed.

- The error margin allowed in this study was $a=0: 05(5 \%)$

To prove the hypothesis rose in this study according to the ranking criterion Cruscal - Wallis must be calculated two statistics, factual and theoretical. Since in the study we have three populations ${ }^{6}$ statistics that will be used is $x^{2}$ statistics.

The formulas used for finding statistics are as follows:

$$
\begin{gathered}
W=\frac{12}{\mathrm{nt}(\mathrm{nt}+1)} \sum \frac{\mathrm{Ri} 2}{\mathrm{ni}}-3(\mathrm{nt}+1) \\
X^{2}=X^{2} 0.05(k-1)=X^{2} 0.05(3-1)=5.99 \mathrm{~s} . d
\end{gathered}
$$

Results of the study after replacing indicators in the formula are:

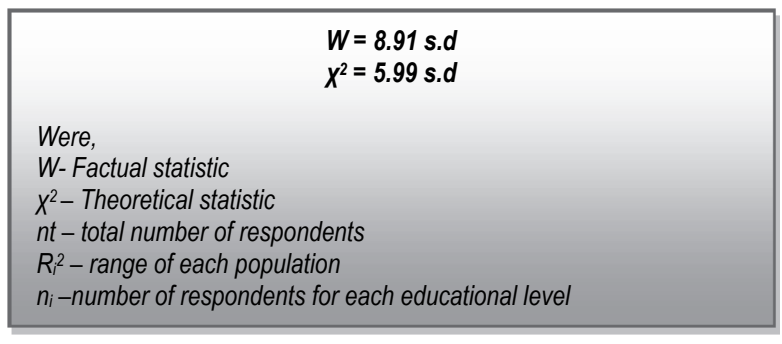

Based on the results we can say that, since $W>x 2$, Ha hypotheses raised in the above is verified. Thus, respondents' education level affects the level of perceived trust in the virtual model of trade. However, as shown in the data tables presented in Annex, regardless of education level of respondents they believe that the impact of their level of confidence in the success of the virtual model of trade is above average.

\section{Impact of accounting in relation between level of trust and success of electronic commerce}

\subsection{Accounting like security factor}

To provide security and development for electronic commerce stakeholders have made continuous efforts to identify influencing factors with the aim to invest in these factors. Is accepted by researchers, that exist a high number of complex factors that influence the level of trust and security of the parties to conduct commercial transactions through virtual networks. For done their contributions to the success of electronic commerce and the development of this trade model also international accounting bodies and accounting specialists themselves have made studies about the positive role they can play. Studies have highlighted the conclusion that the interest groups involved in the trade agreement have created the perception that accounting specialists inspire security (Boulianne and Cho, 2009). Based on this perception, the image of accounting specialist can be used to become parties in virtual trade model.

\subsubsection{Indipendence criteration for examine the impact of accounting in relation between level of trust and success of electronic commerce}

To examine statistically the effects of accounting ${ }^{7}$ in connection trust - success of electronic commerce we have chosen to use the method of control hypotheses based on the criterion of independence. The main reason for selecting this method is: to examine the perception of positive impact of accounting in increasing the level of confidence of buyers depending on their education level. The survey data belong to interval scale and is therefore acceptable use of a

\footnotetext{
6 See table in Annex.

${ }^{7}$ In this part of the study we did not have studied statistically the separate role of the trust services and in particular the role of fiscal legislation but the two indicators together.
} 
parametric method such as the method of control hypothesis based on the criterion of independence. A hypothesis raised in this part of the study is:

Ha: Albanian virtual customer perception about the level of impact of accounting at the level of their trust in the virtual model of trade is dependent on the level of education that they have

$$
\begin{gathered}
\chi 2 \text { factual }=\sum_{i}^{n} \sum_{\mathrm{j}}^{\mathrm{m}} \frac{(\mathrm{fij}-\mathrm{pij}) 2}{\mathrm{pij}} \\
X^{2} \text { theoretical }=X^{2} 0,05(n-1)(m-1)=\chi^{2} 0,05(5-1)(3-1)=15.51 \text { s.d }
\end{gathered}
$$

To follow control procedures in order to establish hypothesis rose above should be calculated the values of two control statistics, statistics theoretical and factual statistics. Statistics used in this statistical model is X2 statistics (Chi-square). The formulas used by this method for finding the control statistics are:

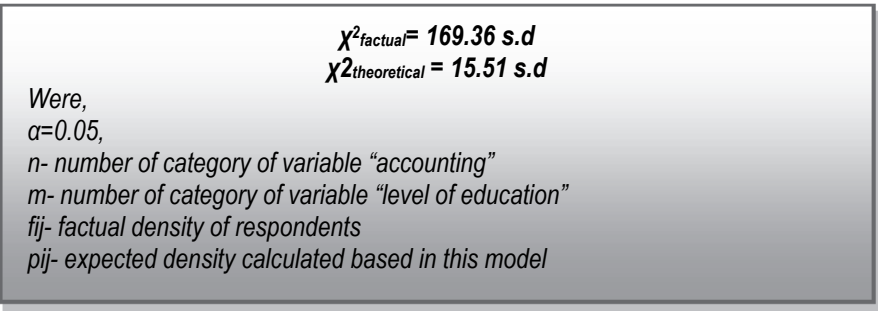

Results ${ }^{8}$ of the study after replacing indices in formulas are as follows:

Based on the results of the study can say that, because $x 2$ factual $>$ X2theoretical, hypothesis raised in the study is verified. Thus, respondents' education level affects the perception that they have regarding the positive impact that accounting have in connection "confidence level - success of electronic commerce". This is an expected result because the largest number of respondents ${ }^{9}$ in this study has completed higher education for economy ${ }^{10}$.

\section{Conclusions}

Studies have proven through factorial methods and structural analyses that the level of trust plays an important role for the successful application of electronic commerce. Also the questionnaire responses built under this study addressed to users who live in Albania show that based in their perception exists a strong positive correlation between trust level and success of electronic commerce.

Safety of virtual trade model, in today's time is supported by two main factors: trust services and fiscal legislation. This conclusion is confirmed also by the analysis of questionnaires directed to virtual buyers in Albania. The analyses shows that with a $95 \%$ degree of certainty in Albania virtual buyers thinks that certification of electronic commerce from an accounting specialist and fiscal accounting are factors that impact positively on increasing the level of perceived trust from them. Increase of the level of trust affects the wider involvement of them in electronic commerce.

\section{References}

Cummings, L. L., and Bromiley, P. "The Organizational Trust Inventory (OTI): Development and Validation," in Trust in Organizations: Frontiers of Theory and Research, R. M. Kramer and T. R. Tyler (eds.), Thousand Oaks, CA: Sage Publications, 1996, pp. 302220.

Doney, P. M., and Cannon, J. P. "An Examination of the Nature of Trust in Buyer-Seller Relationships," Journal of Marketing, April 1997,

\footnotetext{
${ }^{8}$ Pij are calculated taking into account the estimated percentages for each category of variable "accounting impact" upon the assumption that we have no perception depending on educational level, thus is accepted as true null hypothesis.

9112 people in this survey are economists.

${ }^{10}$ Accounting as an academic discipline is developed mainly in higher education degree and in secondary schools of economic education. For this reason the respondents who have less than secondary education or attended a school or other faculties haven't knowledge of accounting.
} 
pp. 35-51.

Morgan, R. M., and Hunt, S. D. "The Commitment-Trust Theory of Relationship Marketing," Journal of Marketing (58), 1994, pp. 20-38.

Ring, P. S., and Van de Ven, A. H. "Developing Processes of Cooperative Inter-organizational Relationships," Academy of Management Review (19), 1994, pp. 90-118.

Smith, J. B., and Barclay, D. W. "The Effects of Organizational Differences and Trust on the Effectiveness of Selling Partner Relationships," Journal of Marketing (51), 1997, pp. 3-21.

Granovetter, M. "Economic Action and Social Structure: The Problem of Embeddedness," American Journal of Sociology (91:3), 1985.

McAllister, D. J. "Affect- and Cognition-Based Trust as Foundations for Interpersonal Cooperation in Organizations," Academy of Management Journal (38:1), 1995, pp. 24-59.

Kim, E. and Tadisina, S. (2007). A model of customers' trust in e-businesses: micro-level inter-party trust formation, The Journal of Computer Information Systems, 48(1), 88-104.

Jarvenpaa, S.L., Tractinsky, N. and Vitale, M. (2000). Consumer trust in an Internet store, Information Technology and Management, 1(1-2), 45-71.

Lee, M.K.O. and Turban, E. (2001). A trust model for consumer Internet shopping, International Journal of Electronic Commerce, 6(1), 75-91.

Gao, Y and Wu, X. (2010). A Cognitive Model Of Trust In E-Commerce: Evidence From A Field Study In China, The Journal of Applied Business Research - January/February 2010 Volume 26, Number 1

Joubert, J and Van Belle, J. (2013). The Role of Trust and Risk in Mobile Commerce Adoption within South Africa, International Journal of Business, Humanities and Technology Vol. 3 No. 2; February 2013

Egger, F. (2003). From interactions to transactions: Designing the Trust Experience for Business-to-Consumer Electronic Commerce.

Brown, I. and Jayakody, R. "B2C e-Commerce Success: a Test and Validation of a Revised Conceptual Model." The Electronic Journal Information Systems Evaluation Volume 11 Issue 3 2008, pp. 167 - 184, available online at www.ejise.com

Palvia, P. (2009) "The role of trust in e-commerce relational exchange: A unified model." Information \& Management. 46, 213-220

Hsu, L. \& Wang, Ch. (2008). A Study of E-trust in Online Auctions, Journal of Electronic Commerce Research, VOL 9, NO 4, 2008 ,

Yoon, H.Sh. (2009), Focusing on consumer-to-consumer trust in electronic commerce with age and gender factors.

Coles, G. (2010), Focusing on consumer-to-consumer trust in electronic commerce with age and gender factors

Mcknight, H. \& Choudhury, V. and Kacmar, Ch. (2002). Developing and Validating Trust Measures for e-Commerce: An Integrative Typology, Information Systems Research,_2 2002 INFORMS Vol. 13, No. 3, September 2002, pp. 334-359

Ho, Sh. (2007), Sociological factors affecting trust development in virtual communities, Proceedings of European and Mediterranean Conference on Information Systems 2007 (EMCIS2007) June 24-26 2007, Polytechnic University of Valencia, Spain www.emcis.org

Corbitt, B.J, Thanasankit, Th. \& Yi, H. (2003). Trust and e-commerce: a study of consumer perceptions, Electronic Commerce Research and Applications 2 (2003) 203-215

Metzger, M. (2004). Privacy, Trust, And Disclosure: Exploring barriers to electronic commerce, Journal of Computer-Mediated Communication

Eid, M. (2011). Determinants of E-Commerce Customer Satisfaction, Trust, and Loyalty in Saudi Arabia, Journal of Electronic Commerce Research, VOL 12, NO 1, 2011

Wan, K. \& Alagar, V., and Ibrahim, N. (2013), An extendet service- oriented architecture for consumer-centric e-commerce, International Journal of Information and Communication Technology Research

Boulianne, E. \& Cho, Ch.H. (2009). The rise and fall of webtrust. Author manuscript, published in "La place de la dimension européenne dans la Comptabilité Contrôle Audit, Strasbourg : France

Shi, J \& Bochmann, G. and Adams, Ch.: A trust model with statistical foundation 
Appendix: Questionnaire

1 - What is your educational level?
a) High
b) Medium
c) lower than medium

2 - Do you think there is a strong connection between your level of confidence for engaged in electronic commerce and the success of the virtual model of trade? Specify a scale from 1-5. ( 1 = not at all, 2 = slightly, $3=$ fair, $4=$ very much, 5 = extremely much)
a) 1
b) 2
c) 3
d) 4
e) 5

3 - Do you think that the accounting impact on the success of the virtual model of trade? Specify a scale from 1-5. $(1=$ not at all, $2=$ slightly, 3 = fair, 4 = very much, 5 = extremely much)
a) 1
b) 2
c) 3
d) 4
e) 5

4 - What is the reason for this perception? Specify

Thank you!

Annex 1.1: Impact of trust level in an range 1-5 in success of electronic commerce. $(1=$ not at all, $2=$ slightly, $3=$ fair, 4 $=$ very much, $5=$ extremely much)

\begin{tabular}{|c|c|c|c|c|c|c|c|c|c|}
\hline No. & Impact range & No. & Impact range & No. & Impact range & No. & Impact range & No. & Impact range \\
\hline 1 & 5 & 42 & 5 & 83 & 4 & 124 & 4 & 165 & 5 \\
\hline 2 & 4 & 43 & 5 & 84 & 3 & 125 & 5 & 166 & 1 \\
\hline 3 & 4 & 44 & 5 & 85 & 3 & 126 & 5 & 167 & 2 \\
\hline 4 & 4 & 45 & 5 & 86 & 3 & 127 & 5 & 168 & 3 \\
\hline 5 & 5 & 46 & 5 & 87 & 3 & 128 & 5 & 169 & 4 \\
\hline 6 & 4 & 47 & 4 & 88 & 3 & 129 & 5 & 170 & 4 \\
\hline 7 & 3 & 48 & 5 & 89 & 4 & 130 & 5 & 171 & 4 \\
\hline 8 & 4 & 49 & 4 & 90 & 4 & 131 & 5 & 172 & 5 \\
\hline 9 & 5 & 50 & 4 & 91 & 4 & 132 & 5 & 173 & 4 \\
\hline 10 & 5 & 51 & 5 & 92 & 4 & 133 & 5 & 174 & 4 \\
\hline 11 & 5 & 52 & 4 & 93 & 4 & 134 & 5 & 175 & 4 \\
\hline 12 & 4 & 53 & 4 & 94 & 4 & 135 & 4 & 176 & 4 \\
\hline 13 & 2 & 54 & 5 & 95 & 5 & 136 & 4 & 177 & 5 \\
\hline 14 & 3 & 55 & 4 & 96 & 5 & 137 & 5 & 178 & 5 \\
\hline 15 & 4 & 56 & 5 & 97 & 4 & 138 & 5 & 179 & 5 \\
\hline 16 & 5 & 57 & 5 & 98 & 4 & 139 & 5 & 180 & 1 \\
\hline 17 & 5 & 58 & 5 & 99 & 4 & 140 & 5 & 181 & 4 \\
\hline 18 & 5 & 59 & 5 & 100 & 4 & 141 & 4 & 182 & 3 \\
\hline 19 & 4 & 60 & 4 & 101 & 5 & 142 & 5 & 183 & 3 \\
\hline 20 & 4 & 61 & 4 & 102 & 5 & 143 & 5 & 184 & 3 \\
\hline 21 & 4 & 62 & 5 & 103 & 3 & 144 & 5 & 185 & 2 \\
\hline 22 & 4 & 63 & 5 & 104 & 3 & 145 & 4 & 186 & 1 \\
\hline 23 & 5 & 64 & 5 & 105 & 3 & 146 & 4 & 187 & 5 \\
\hline 24 & 5 & 65 & 5 & 106 & 2 & 147 & 4 & 188 & 5 \\
\hline 25 & 4 & 66 & 4 & 107 & 4 & 148 & 5 & 189 & 5 \\
\hline 26 & 4 & 67 & 4 & 108 & 5 & 149 & 4 & 190 & 5 \\
\hline 27 & 4 & 68 & 4 & 109 & 3 & 150 & 5 & 191 & 5 \\
\hline 28 & 3 & 69 & 4 & 110 & 2 & 151 & 3 & 192 & 4 \\
\hline 29 & 2 & 70 & 4 & 111 & 2 & 152 & 4 & 193 & 1 \\
\hline 30 & 2 & 71 & 4 & 112 & 4 & 153 & 4 & 194 & 5 \\
\hline 31 & 4 & 72 & 4 & 113 & 5 & 154 & 5 & 195 & 1 \\
\hline 32 & 5 & 73 & 5 & 114 & 5 & 155 & 5 & 196 & 1 \\
\hline 33 & 5 & 74 & 3 & 115 & 5 & 156 & 5 & 197 & 1 \\
\hline 34 & 4 & 75 & 4 & 116 & 5 & 157 & 5 & 198 & 2 \\
\hline 35 & 4 & 76 & 4 & 117 & 5 & 158 & 4 & 199 & 3 \\
\hline 36 & 4 & 77 & 4 & 118 & 5 & 159 & 4 & 200 & 4 \\
\hline 37 & 4 & 78 & 5 & 119 & 5 & 160 & 2 & 201 & 4 \\
\hline 38 & 4 & 79 & 5 & 120 & 5 & 161 & 1 & 202 & 5 \\
\hline 39 & 4 & 80 & 5 & 121 & 5 & 162 & 1 & 203 & 5 \\
\hline 40 & 5 & 81 & 4 & 122 & 5 & 163 & 2 & & \\
\hline 41 & 5 & 82 & 4 & 123 & 4 & 164 & 2 & & \\
\hline
\end{tabular}


Annex 1.2 : Perceived level of trust depended from educational level

\begin{tabular}{|c|c|c|c|c|c|c|c|c|}
\hline No. & High education & Range & No. & Secondary education & Range & No. & other & Range \\
\hline 1 & 5 & 161 & 1 & 4 & 79.5 & 1 & 5 & 161 \\
\hline 2 & 4 & 79.5 & 2 & 4 & 79.5 & 2 & 5 & 161 \\
\hline 3 & 4 & 79.5 & 3 & 4 & $\begin{array}{l}79.5 \\
\end{array}$ & 3 & 5 & 161 \\
\hline 4 & 4 & 79.5 & 4 & 5 & 161 & $\overline{4}$ & 5 & 161 \\
\hline 5 & 5 & 161 & 5 & 5 & 161 & 5 & 5 & 161 \\
\hline 6 & 4 & 79.5 & 6 & 5 & 161 & 6 & 5 & 161 \\
\hline 7 & 3 & 31 & 7 & 4 & 79.5 & 7 & 5 & 161 \\
\hline 8 & 4 & 79.5 & 8 & 4 & 79.5 & 8 & 4 & 79.5 \\
\hline 9 & 5 & 161 & 9 & 4 & 79.5 & 9 & 4 & 79.5 \\
\hline 10 & 5 & 161 & 10 & 3 & 31 & 10 & 5 & 161 \\
\hline 11 & 5 & 161 & 11 & 3 & 31 & 11 & 5 & 161 \\
\hline 12 & 4 & 79.5 & 12 & 3 & 31 & 12 & 5 & 161 \\
\hline 13 & 2 & 15.5 & 13 & 3 & 31 & 13 & 5 & 161 \\
\hline 14 & 3 & 31 & 14 & 3 & 31 & 14 & 4 & 79.5 \\
\hline 15 & 4 & 79.5 & 15 & 4 & 79.5 & 15 & 5 & 161 \\
\hline 16 & 5 & 161 & 16 & 4 & 79.5 & 16 & 5 & 161 \\
\hline 17 & 5 & 161 & 17 & 4 & 79.5 & 17 & 5 & 161 \\
\hline 18 & 5 & 161 & 18 & 4 & $\begin{array}{l}79.5 \\
\end{array}$ & 18 & 4 & 79.5 \\
\hline 19 & 4 & 79.5 & 19 & 4 & 79.5 & 19 & 4 & 79.5 \\
\hline 20 & 4 & 79.5 & 20 & 4 & $\begin{array}{l}79.5 \\
\end{array}$ & 20 & 4 & $\begin{array}{l}79.5 \\
\end{array}$ \\
\hline 21 & 4 & 79.5 & 21 & 5 & 161 & 21 & 5 & 161 \\
\hline 22 & 4 & 79.5 & 22 & 5 & 161 & 22 & 4 & 79.5 \\
\hline 23 & 5 & 161 & 23 & 4 & 79.5 & 23 & 5 & 161 \\
\hline 24 & 5 & 161 & 24 & 4 & 79.5 & & & \\
\hline 25 & 4 & 79.5 & 25 & 4 & 79.5 & & & \\
\hline 26 & 4 & 79.5 & 26 & 4 & 79.5 & & & \\
\hline 27 & 4 & 79.5 & 27 & 5 & 161 & & & \\
\hline 28 & 3 & 31 & 28 & 5 & 161 & & & \\
\hline 29 & 2 & 15.5 & 29 & 3 & 31 & & & \\
\hline 30 & 2 & 15.5 & 30 & 3 & 31 & & & \\
\hline 31 & 4 & 79.5 & 31 & 3 & 31 & & & \\
\hline 32 & 5 & 161 & 32 & 2 & 15.5 & & & \\
\hline 33 & 5 & 161 & 33 & 4 & 79.5 & & & \\
\hline 34 & 4 & 79.5 & 34 & 5 & 161 & & & \\
\hline 35 & 4 & 79.5 & 35 & 3 & 31 & & & \\
\hline 36 & 4 & 79.5 & 36 & 2 & 15.5 & & & \\
\hline 37 & 4 & 79.5 & 37 & 2 & 15.5 & & & \\
\hline 38 & 4 & 79.5 & 38 & 4 & 79.5 & & & \\
\hline 39 & 4 & 79.5 & 39 & 5 & 161 & & & \\
\hline 40 & 5 & 161 & 40 & 5 & 161 & & & \\
\hline 41 & 5 & 161 & 41 & 5 & 161 & & & \\
\hline 42 & 5 & 161 & 42 & 5 & 161 & & & \\
\hline 43 & 5 & 161 & 43 & 5 & 161 & & & \\
\hline 44 & 5 & 161 & 44 & 5 & 161 & & & \\
\hline 45 & 5 & 161 & 45 & 5 & 161 & & & \\
\hline 46 & 5 & 161 & 46 & 5 & 161 & & & \\
\hline 47 & 4 & 79.5 & 47 & 5 & 161 & & & \\
\hline 48 & 5 & 161 & 48 & 5 & 161 & & & \\
\hline 49 & 4 & $\begin{array}{l}79.5 \\
\end{array}$ & 49 & 4 & $\begin{array}{l}79.5 \\
\end{array}$ & & & \\
\hline 50 & 4 & 79.5 & 50 & 4 & 79.5 & & & \\
\hline 51 & 5 & 161 & 51 & 5 & 161 & & & \\
\hline
\end{tabular}




\begin{tabular}{|c|c|c|c|c|c|c|c|c|}
\hline 52 & 4 & 79.5 & 52 & 5 & 161 & & & \\
\hline 53 & 4 & 79.5 & 53 & 5 & 161 & & & \\
\hline 54 & 5 & 161 & & & & & & \\
\hline 55 & 4 & 79.5 & & & & & & \\
\hline 56 & 5 & 161 & & & & & & \\
\hline 57 & 5 & 161 & & & & & & \\
\hline 58 & 5 & 161 & & & & & & \\
\hline 59 & 5 & 161 & & & & & & \\
\hline 60 & 4 & 79.5 & & & & & & \\
\hline 61 & 4 & 79.5 & & & & & & \\
\hline 62 & 5 & 161 & & & & & & \\
\hline 63 & 5 & 161 & & & & & & \\
\hline 64 & 5 & 161 & & & & & & \\
\hline 65 & 5 & 161 & & & & & & \\
\hline 66 & 4 & 79.5 & & & & & & \\
\hline 67 & 4 & 79.5 & & & & & & \\
\hline 68 & 4 & 79.5 & & & & & & \\
\hline 69 & 4 & 79.5 & & & & & & \\
\hline 70 & 4 & 79.5 & & & & & & \\
\hline 71 & 4 & 79.5 & & & & & & \\
\hline 72 & 4 & 79.5 & & & & & & \\
\hline 73 & 5 & 161 & & & & & & \\
\hline 74 & 3 & 31 & & & & & & \\
\hline 75 & 3 & 31 & & & & & & \\
\hline 76 & 4 & 79.5 & & & & & & \\
\hline 77 & 4 & 79.5 & & & & & & \\
\hline 78 & 5 & 161 & & & & & & \\
\hline 79 & 5 & 161 & & & & & & \\
\hline 80 & 5 & 161 & & & & & & \\
\hline 81 & 5 & 161 & & & & & & \\
\hline 82 & 4 & 79.5 & & & & & & \\
\hline 83 & 4 & 79.5 & & & & & & \\
\hline 84 & 2 & 15.5 & & & & & & \\
\hline 85 & 1 & 5 & & & & & & \\
\hline 86 & 1 & 5 & & & & & & \\
\hline 87 & 2 & 15.5 & & & & & & \\
\hline 88 & 2 & 15.5 & & & & & & \\
\hline 89 & 5 & 161 & & & & & & \\
\hline 90 & 1 & 5 & & & & & & \\
\hline 91 & 2 & 15.5 & & & & & & \\
\hline 92 & 3 & 31 & & & & & & \\
\hline 93 & 4 & 79.5 & & & & & & \\
\hline 94 & 4 & 79.5 & & & & & & \\
\hline 95 & 4 & 79.5 & & & & & & \\
\hline 96 & 5 & 161 & & & & & & \\
\hline 97 & 4 & 79.5 & & & & & & \\
\hline 98 & 4 & 79.5 & & & & & & \\
\hline 99 & 4 & 7.5 & & & & & & \\
\hline 100 & 4 & 79.5 & & & & & & \\
\hline 101 & 5 & 161 & & & & & & \\
\hline 100 & 5 & 161 & & & & & & \\
\hline 103 & 5 & 161 & & & & & & \\
\hline 104 & 1 & 5 & & & & & & \\
\hline 105 & 4 & 79.5 & & & & & & \\
\hline
\end{tabular}




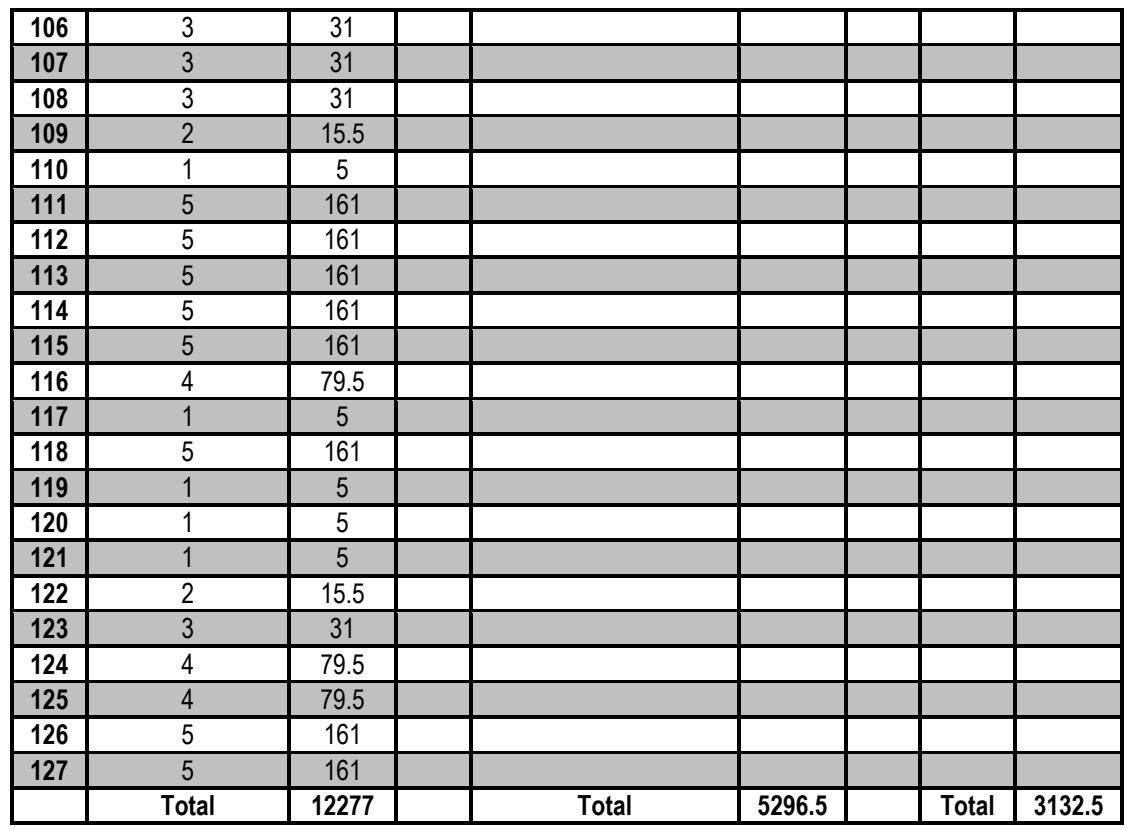

Annex 1.3: Perception of buyers for range of accounting impact in trust of virtual commerce depended from educational level

\begin{tabular}{|c|c|c|c|c|c|c|c|}
\hline \multirow{2}{*}{ Range of accounting impact } & \multicolumn{3}{|c|}{ Educational level } \\
\cline { 2 - 9 } & \multicolumn{2}{|c|}{$\begin{array}{c}\text { Higher } \\
\text { fij pji }\end{array}$} & \multicolumn{3}{|c|}{$\begin{array}{c}\text { Secondary } \\
\text { fij pji }\end{array}$} & \multicolumn{3}{|c|}{$\begin{array}{c}\text { other } \\
\text { fij pji }\end{array}$} & Total \\
\hline Not at all & 0 & 23.14778325 & 19 & 9.660098522 & 18 & 4.192118227 & 37 \\
\hline Slightly & 10 & 26.27586207 & 27 & 10.96551724 & 5 & 4.75862069 & 42 \\
\hline Fair & 35 & 26.27586207 & 7 & 10.96551724 & 0 & 4.75862069 & 42 \\
\hline Very much & 66 & 41.29064039 & 0 & 17.23152709 & 0 & 7.477832512 & $\mathbf{6 6}$ \\
\hline Extremely much & 16 & 10.00985222 & 0 & 4.177339901 & 0 & 1.812807882 & 16 \\
\hline Total & 127 & 127 & $\mathbf{5 3}$ & $\mathbf{5 3}$ & $\mathbf{2 3}$ & $\mathbf{2 3}$ & $\mathbf{2 0 3}$ \\
\hline
\end{tabular}

